\title{
Health-related quality of life in patients with systemic lupus erythematosus in Midwest Brazil
}

\author{
Maria Gorette dos Reis ${ }^{1}$, Izaias Pereira da Costa $^{2}$
}

\begin{abstract}
Introduction/Objective: Evaluate the quality of life (QOL) of women with systemic lupus erythematosus (SLE) and the association between QOL domains, measured by the World Health Organization Quality of Life Group (WHOQOL-100) assessment instrument, and disease activity. Patients and Methods: A cross-sectional analytic study involving 95 patients with SLE, according to the American College of Rheumatology (ACR) criteria, aged 20-49 years, attended at the University Center of Universidade Federal de Mato Grosso do Sul, Campo Grande, MS. We used the following instruments: demographic and clinical data collection form and WHOQOL-100 instrument. Evaluation of disease activity was performed by SLEDAI. On statistical analysis, we applied Student's t-test, ANOVA, and Pearson's correlation. Results: Group-case: 79 female with mild to moderate SLE activity (SLEDAI $=1-10)$ and severe activity $($ SLEDAI $\geq$ 11). Control group: 16 female with inactive SLE (SLEDAI =0). All domains of WHOQOL-100 proved to be affected, with significant difference $(\mathrm{P}<0.005)$ between the case and control groups in which there was a better perception of QOL in the domain Spirituality and worst perception of QOL in the domain Environment. When confronting QOL domains with education, we detected a significant difference $(\mathrm{P}<0.05)$ in the Physical, Psychological, Level of independence, and Environment domains. The comparison between QOL and disease activity was significant $(\mathrm{P}<0.005)$ in three domains: Physical, Psychological, and Environment. Conclusion: SLE with intense activity determines a worse QOL condition than inactive SLE. The assessment of QOL enables the knowledge of disease and treatment impact in a contextualized way, which can render more appropriate and more comprehensive interventions.
\end{abstract}

Keywords: quality of life, women's health, systemic lupus erythematosus.

\section{INTRODUCTION}

Assessment of quality of life (QOL) of women with systemic lupus erythematosus (SLE) can be as important as measurements of morbidity and mortality. ${ }^{1}$ The effect of changes caused by the disease process and therapy in the clinical course of disease demands actions that improve the QOL as an essential tool of satisfaction for patients and health professionals. $^{2}$

In periods of intense inflammatory activity, the widespread deposition of immune complexes in sites like blood vessel walls produces inflammation and functional changes in various organs, which gives the disease its systemic character. ${ }^{1,3,4}$ These periods are marked by severe signs and symptoms and clinical and laboratory changes, requiring the use of high dose steroids and, quite often, immunosuppressants. ${ }^{1}$

Several signs and symptoms may interfere with QOL during periods of SLE activity, such as vasculitis causing skin rash; painful lesions and hyperemia in palms and soles, palate or limb regions; fever without infection; weight loss; headache; alopecia; asthenia; mialgia; eye problems; hepatomegaly; splenomegaly; and adenopathy. ${ }^{3}$

Although the etiology remains unclear, the disease is strongly influenced by genetic, hormonal (estrogen),

\footnotetext{
Received on 09/15/2009. Accepted on 06/01/2010. We declare no conflicts of interest. Approved by the Research Ethics Committee (CEP CEP/UFMS), under the Protocol No 363/06 of August 7, 2006.

Rheumatology Section of Hospital Universitario da Universidade Federal de Mato Grosso do Sul - NHU-UFMS.

1. PhD student - Post-graduation Program of Health and Development in the Midwest Region, UFMS. Associate Professor at the Clinical Nursing of Nursing Department, UFMS.

2. PhD - Professor at Post-graduation Program of Health and Development in the Midwest Region, UFMS. Associate Professor, Discipline of Rheumatology, Department of Clinical Medicine, Faculdade de Medicina da UFMS. Chief of Rheumatology at Rheumatology Section of NHU-UFMS.

Correspondence to: Maria Gorette dos Reis. Rua Washington Luís, 325. Campo Grande, MS, Brazil. CEP: 79051-060. Phone/Fax: 55 (67) 3345-7353;

55 (67) 9984-9508.
} 
environmental (ultraviolet radiation, drugs), infectious (viral), and psychological stress factors, which participate in its pathogenesis. ${ }^{5.6}$

SLE is one of the most common autoimmune diseases in young women, with the highest incidence in the age group of 15-40 years, at a ratio of six women for each man. Therefore, the odds of developing this predominantly female disease differ between genders. ${ }^{7}$

The QOL issue incorporated into the heath practice of professionals has been designated as health-related quality of life and used in clinical setting to express the physical and psychosocial impact caused by physical and biological changes produced by disease and therapies that interfere with daily life conditions. ${ }^{80-10}$

The attempt to achieve QOL, as well as seeking to define it, has followed the historical and cultural development of mankind. ${ }^{11}$ The QOL construct is very comprehensive, reflecting the historical moment, social class, and culture of the individual, since it comes from experience, knowledge, and values both individual and collective.

One definition of QOL has been proposed by a study group on QOL of the World Health Organization (WHO), World Health Organization Quality of Life Group (WHOQOL): "An individual's perception of his/her position in life in the context of the culture and value systems in which he/she lives, and in relation to his/her goals, expectations, standards and concerns." ${ }^{\prime 2}$

The WHOQOL-100 is a generic QOL instrument developed by the WHO in 1998 from a multicenter study. It contains 100 questions divided into 24 groups of four questions whose answers are punctuated by scores that range from 0 to 1.0 for each domain. Each group of four questions refers to a facet. A given number of facets constitute a domain. The domains with their respective facets are: Physical (pain, discomfort, energy and fatigue, sleep and rest); Psychological (positive feelings, thinking, learning, memory, concentration, self-esteem, body image and appearance, and negative feelings); Level of Independence (mobility, daily activities, dependence on accompaniment or treatment and work capacity); Social (personal relationships, social support, and sexual activity); Environment (physical safety and security: the home environment, financial, health care, social care, recreation/rest, physical environment, and transport); and Spirituality (spirituality, religion, personal beliefs)..$^{12}$

Among the various instruments for measuring QOL in literature, the WHOQOL-100 was chosen for this study because of the breadth of its domains and facets, structure of the instrument, the complexity of SLE due to impairments that patients may develop, and the possibility of self-administration by the selected population. The aim of this study was to evaluate the perceived health-related QOL of adult women with SLE, considering the association between QOL and disease activity.

\section{PATIENTS AND METHODS}

This was a cross-sectional analytical study developed in the Department of Rheumatology of the Núcleo do Hospital Universitário da Universidade Federal de Mato Grosso do Sul (NHU-UFMS) and included 95 women, with data collected from March 2, 2007, through September 2, 2008.

Inclusion criteria were presence of records in the NHUUFMS, female, age 20-49 years, meeting at least four criteria for SLE diagnosis (according to the American College of Rheumatology-ACR-1982), ability to communicate verbally or in writing on interview and data collection instrument, agree to participate in the study, and sign informed consent. Exclusion criteria were presence of other chronic infectious diseases non-associated with SLE activity and chronicity, and suspected or confirmed pregnancy.

The instruments used for data collection were: form for collecting demographic and clinical data and WHOQOL-100. The Systemic Lupus Erythematosus Disease Activity Index (SLEDAI $)^{14}$ was used to classify groups of participants based on disease activity index. The case group consisted of 79 women with mild to moderate SLE activity (SLEDAI $=1-10)$ and severe activity (SLEDAI $\geq 11$ ). The control group consisted of women with inactive SLE (SLEDAI $=0$ ).

Completion of WHOQOL-100 was performed preferentially by the participant herself, respecting the privacy requirements of the clinical setting. When indicated, due to clinical status or education level, the filling was carried out with assistance and support directly from the researcher. ${ }^{13}$ In these situations, the questions were read by the researcher and the participant indicated her response options. The question was repeated as often as was needed, without adding explanations that would direct the response.

Study complied with the Guidelines and Standards for Human Research, according to Resolution 196/96 of the National Research Council, and obtained approval of the Research Ethics Committee (CEP CEP/UFMS), under the Protocol No 363/06 of August 7, 2006.

For statistical analysis were applied the Student's t-test and analysis of variance (ANOVA) for the domains addressed in WHOQOL-100, and Pearson's correlation for continuous 
demographic variables. Through statistical analysis, we attempted to detect significant differences $(\mathrm{P}<0.05)$ when there was an association between the QOL domains and case and control groups, and also between these domains and demographic and clinical variables.

\section{RESULTS}

Of the 95 women who participated in this study, 45 (47.4\%) had primary education and $50(52.6 \%)$ had mid-level education or higher. As for marital status, $67.4 \%$ lived with a partner and $32.6 \%$ lived alone or with children and families. Regarding the origin, $49.5 \%$ were from Campo Grande. Among the 48 who came from other cities, $44(91.7 \%)$ came from the interior of Mato Grosso do Sul, three (6.2\%) from other states, and one (2.1\%) from Paraguay. All study participants were treated at NHU-UFMS with funds from the SUS (a Brazilian unified healthcare system). Only $16.8 \%$ sporadically used private healthcare systems to perform some tests (Table 1).

The average age of participants in the research period was 34.22 years $( \pm 8.29)$, the mean age at diagnosis was 27.57 years $( \pm 8.95)$, and the time of SLE during the study period was 6.69 years (Table 2).

In the present study sample, the disease was very active (SLEDAI $\geq 11)$ in 21 (22.1\%) of participants, mild to moderate activity (SLEDAI $=1-10)$ in $58(61.1 \%)$, and inactivity $($ SLEDAI $=0)$ in $16(16.8 \%)$. Therefore, the first $79(83.2 \%)$ patients mentioned comprised the case group and only the last $16(16.8 \%)$ formed the control group (Table 3).

In all study participants, the WHOQOL-100 questionnaire was applied and we identified mean scores of QOL according to each QOL domain (Table 4.) As a basis for calculating these scores, we used the reference values ( 0 to 1.0 ) indicated by the WHOQOL group. Thus, the Spirituality domain, which presented the highest score (0.79), was assessed as the domain with the best perception of QOL and, the Environment domain, which was associated with the lowest score $(0.53)$, was considered the worst perception of QOL. Analysis of variance (ANOVA) was used in all patients to assess possible differences between mean scores of the six QOL domains of WHOQOL-100. Statistical analysis identified significant differences between all QOL domains (physical, psychological, level of independence, social relationships, environment, and spirituality) in all participants, with $95 \%$ confidence interval $(\mathrm{P}<0.05$, Table 4$)$.

In this research, the most prevalent results were those associated with QOL and education of participants with SLE. When confronting the domains of QOL with the results

\section{Table 1}

Sociodemographic characteristics of adult women with systemic lupus erythematosus treated at NHU-UFMS: marital status, education, origin, and use of healthcare system. Campo Grande, MS, 2007-2008 (N: 95)

\begin{tabular}{|c|c|c|c|}
\hline \multicolumn{2}{|c|}{ Sociodemographic Variables } & \multirow{2}{*}{$\frac{\mathbf{n}}{45}$} & \multirow{2}{*}{$\frac{\%}{47.4}$} \\
\hline \multirow{3}{*}{ Education } & Primary School & & \\
\hline & High School & 39 & 41.0 \\
\hline & Superior Education & 11 & 11.6 \\
\hline \multirow{2}{*}{ Origin } & Campo Grande & 47 & 49.5 \\
\hline & Other cities* & 48 & 50.5 \\
\hline \multirow{2}{*}{ Marital status } & With a partner & 64 & 67.4 \\
\hline & Without a partner & 31 & 32.6 \\
\hline \multirow{2}{*}{ Healthcare system } & SUS & 79 & 83.2 \\
\hline & Private & 16 & 16.8 \\
\hline
\end{tabular}

Includes 44 women (91.7\%) from the interior of Mato Grosso do Sul, three (6.2\%) from other states, and one (2.1\%) from another country.

\section{Table 2}

Mean age, age at diagnosis, and time of diagnosis in adult women with systemic lupus erythematosus (SLE) treated at NHU-UFMS. Campo Grande, MS, 2007-2008

\begin{tabular}{lccc}
\hline Variable & $\mathbf{n}$ & Mean & SD* $^{*}$ \\
\hline Age (years) & 95 & 34.22 & \pm 8.29 \\
Age at SLE diagnosis (years) & 95 & 27.57 & \pm 8.95 \\
Age at diagnosis (anos) & 95 & 6.69 & \pm 6.04 \\
\hline${ }^{*}$ SD $=$ standard deviation & & &
\end{tabular}

Table 3

Disease activity in adult women with systemic lupus erythematosus (SLE) treated at NHUUFMS, second score of the Systemic Lupus Erythematosus Disease Activity Index (SLEDAI), by study group. Campo Grande, MS, 2007-2008

\begin{tabular}{llccc}
\hline \multirow{2}{*}{ Case } & Intense & $\begin{array}{c}\text { SLEDAI } \\
\text { score }\end{array}$ & $\mathbf{n}$ & \% \\
\cline { 2 - 5 } & Mild to moderate & $1-10$ & 58 & 61.1 \\
Control & Inactive & 0 & 16 & 16.8 \\
Total & & & 95 & 100 \\
\hline
\end{tabular}


for education of women with SLE, a significant difference $(\mathrm{P}<0.05)$ was identified in the Physical, Psychological, Level of Independence, and Environment domains, which leads us to conclude that there is a better QOL perception in these domains (Table 5).

To compare the QOL of women with SLE in all domains of WHOQOL-100 with the levels of disease activity, we applied the ANOVA test, with $95 \%$ reliability. Significant difference $(\mathrm{P}<0.05)$ was found in three areas: Physical, Psychological, and Environment. It was found that adult women with intense SLE activity showed worse QOL perception than adult women with SLE without activity (Table 6)

\section{DISCUSSION}

The level of education appears to be associated with QOL. ${ }^{15}$ In all participants, the relevant results were those in which higher levels of education showed better perception of QOL in Physical, Psychological, Level of Independence, and Environment domains. For Martinez ${ }^{16}$ higher levels of education among women with SLE determine the adoption of cognitive and behavioral strategies to better cope with situations, representing higher level of mental preparation and shifting the focus of emotional problems. Therefore, the higher the education, the better the perceived QOL of women with SLE, in the domains indicated.

According to reports from participants themselves, the most significant limitations affecting the relationship with their partners and family members included pain, fatigue, stress, decreased self-esteem, altered self-image, decreased libido, physical disability, medication use, need for support from other

\section{Table 4}

Quality of life (QOL) domains of the World Health Organization Quality of Life Group (WHOQOL-100), averaged scores of adult women with systemic lupus erythematosus (SLE) treated at NHU-

UFMS. Campo Grande, MS, 2007-2008

\begin{tabular}{|c|c|c|c|c|}
\hline QOV Domains & $\mathbf{n}$ & QOL Mean Scores* & SD & $\mathbf{P}$ \\
\hline Physical & 95 & 0.60 & 0.13 & \multirow{6}{*}{$<0.001$} \\
\hline Psychological & 95 & 0.60 & 0.11 & \\
\hline Level of Independence & 95 & 0.61 & 0.17 & \\
\hline Social & 95 & 0.65 & 0.17 & \\
\hline Environment & 95 & 0.53 & 0.13 & \\
\hline Spirituality & 95 & 0.79 & 0.16 & \\
\hline
\end{tabular}

${ }^{*}$ Reference value for QOL mean scores: 0.0 to 1.0

$\mathrm{SD}=$ standard deviation; $\mathrm{P}$ (value) = level of statistical significance (value $<0.005)$. people, and financial difficulties. Because they are young and at reproductive age, these women reported that their marital and family QOL are affected. Therefore, the affective relations of women with SLE and their partners also go through processes of adaptation at different stages of disease.

These reports are consistent with the literature, which shows that children who live with people with SLE (partner, children, and other relatives) are faced with emotional reactions, clinical fluctuations, and interference in social role, work, and performance of daily activities. ${ }^{17}$

Other studies show similarity to the results of this research with respect to mean age at the time of diagnosis., ${ }^{2,16,18-20,24}$ The diagnosis of SLE is always a nuisance, ${ }^{21}$ leaving young women anxious because it occurs in a productive and crucial phase of their life, a time to stabilize their relationships, constitute a family, or choose a career. The author's argument quoted previously is consistent with the results of this study, as the

\section{Table 5}

QOL domains of the World Health Organization Quality of Life Group (WHOQOL-100) in terms of education of adult women with systemic lupus erythematosus (SLE) treated at NHU-UFMS. Campo Grande, MS, 2007-2008 (N: 95)

\begin{tabular}{|c|c|c|c|c|c|}
\hline QOL Domains & Education & $\mathrm{n}$ & $\begin{array}{l}\text { QOL Mean } \\
\text { Scores* }\end{array}$ & SD & $\mathrm{P}$ \\
\hline \multirow{3}{*}{ Physical } & Primary & 45 & 0.56 & 0.12 & \multirow{3}{*}{0.001} \\
\hline & High & 39 & 0.65 & 0.12 & \\
\hline & Superior & 11 & 0.54 & 0.16 & \\
\hline \multirow{3}{*}{ Psychological } & Primary & 45 & 0.56 & 0.11 & \multirow{3}{*}{0.002} \\
\hline & High & 39 & 0.64 & 0.10 & \\
\hline & Superior & 11 & 0.56 & 0.11 & \\
\hline \multirow{3}{*}{$\begin{array}{l}\text { Level of } \\
\text { Independence }\end{array}$} & Primary & 45 & 0.55 & 0.16 & \multirow{3}{*}{0.001} \\
\hline & High & 39 & 0.68 & 0.14 & \\
\hline & Superior & 11 & 0.62 & 0.20 & \\
\hline \multirow{3}{*}{$\begin{array}{l}\text { Social } \\
\text { Relationships }\end{array}$} & Primary & 45 & 0.60 & 0.16 & \multirow{3}{*}{0.06} \\
\hline & High & 39 & 0.71 & 0.16 & \\
\hline & Superior & 11 & 0.66 & 0.20 & \\
\hline \multirow{3}{*}{ Environment } & Primary & 45 & 0.47 & 0.11 & \multirow{3}{*}{$\begin{array}{c}< \\
0.001\end{array}$} \\
\hline & High & 39 & 0.60 & 0.11 & \\
\hline & Superior & 11 & 0.53 & 0.16 & \\
\hline \multirow{3}{*}{ Spirituality } & Primary & 45 & 0.76 & 0.13 & \multirow{3}{*}{0.459} \\
\hline & High & 39 & 0.81 & 0.17 & \\
\hline & Superior & 11 & 0.80 & 0.20 & \\
\hline
\end{tabular}

${ }^{*}$ Reference value for QOL mean scores: 0.0 to 1.0.

$\mathrm{SD}=$ standard deviation; $\mathrm{P}($ value $)=$ level of statistical significance (value $<0.005)$. 
Table 6

QOL domains of the World Health Organization Quality of Life Group (WHOQOL-100) in relation to disease activity in adult women with systemic lupus erythematosus (SLE) treated at NHU-UFMS. Campo Grande, MS, 2007-2008. (N: 95)

\begin{tabular}{|c|c|c|c|c|c|}
\hline Domínio de QV & $\begin{array}{l}\text { LES } \\
\text { Activity }\end{array}$ & $\mathbf{n}$ & $\begin{array}{c}\text { QOL } \\
\text { Mean } \\
\text { Scores* }\end{array}$ & SD & $\mathbf{P}$ \\
\hline \multirow{3}{*}{ Physical } & Intense & 21 & 0.54 & 0.16 & \multirow{3}{*}{0.049} \\
\hline & Moderate & 58 & 0.60 & 0.12 & \\
\hline & Inactive & 16 & 0.65 & 0.12 & \\
\hline \multirow{3}{*}{ Psychological } & Intense & 21 & 0.55 & 0.11 & \multirow{3}{*}{0.028} \\
\hline & Moderate & 58 & 0.60 & 0.12 & \\
\hline & Inactive & 16 & 0.65 & 0.08 & \\
\hline \multirow{3}{*}{$\begin{array}{l}\text { Level of } \\
\text { Independence }\end{array}$} & Intense & 21 & 0.54 & 0.17 & \multirow{3}{*}{0.095} \\
\hline & Moderate & 58 & 0.62 & 0.16 & \\
\hline & Inactive & 16 & 0.65 & 0.16 & \\
\hline \multirow{3}{*}{$\begin{array}{l}\text { Social } \\
\text { Relationships }\end{array}$} & Intense & 21 & 0.61 & 0.15 & \multirow{3}{*}{0.058} \\
\hline & Moderate & 58 & 0.64 & 0.18 & \\
\hline & Inactive & 16 & 0.74 & 0.16 & \\
\hline \multirow{3}{*}{ Environment } & Intense & 21 & 0.47 & 0.13 & \multirow{3}{*}{0.034} \\
\hline & Moderate & 58 & 0.54 & 0.13 & \\
\hline & Inactive & 16 & 0.58 & 0.11 & \\
\hline \multirow{3}{*}{ Spirituality } & Intense & 21 & 0.76 & 0.14 & \multirow{3}{*}{0.658} \\
\hline & Moderate & 58 & 0.79 & 0.16 & \\
\hline & Inactive & 16 & 0.81 & 0.17 & \\
\hline
\end{tabular}

${ }^{*}$ Reference value for QOL mean scores: 0.0 to 1.0.

$\mathrm{SD}=$ standard deviation; $\mathrm{P}($ value $)=$ level of statistical significance $($ value $<0.005)$

SLE patients were on average 34 years old, but at the time of SLE diagnosis they were on average six years younger.

The total number of women with active disease (83.2\%) was close to results reported by Khanna et al. ${ }^{20}$ who found disease activity in $70 \%$ of the sample surveyed. The presence of activity, albeit mild, is manifested by new symptoms, clinical and laboratory signs, another organ involvement, or worsening of an organ already affected. ${ }^{1,22,23}$

Several studies have shown that in individuals with SLE, QOL is impaired in different domains, compared with general population. ${ }^{24-26}$ QOL impairment is due to physical and emotional changes caused by the disease process, especially during periods of SLE exacerbation. In this study, although all QOL domains were affected in both groups (case group and control group), in general, SLE patients had a better perception of QOL in the Spirituality domain and worse perception in the Environment domain. One must take into account that the QOL domains are interrelated, since human beings are a holistic and indivisible whole. ${ }^{27}$

In Psychological domain, for example, there is involvement of disease physical effect repercussion and its potential severity, impact on performance of daily activities by functional limitations and pain, effect of altered self-image and selfesteem on physical appearance, fatigue, memory changes, negative feelings, difficulties in personal relationships, lack of social support, dissatisfaction in the sexual sphere and other areas. The same interrelation of reasoning applies to other domains.

Participants showed better QOL perception in the Spirituality domain (Table 4), with higher scores on the answers to the WHOQOL-100 questions correlated with personal beliefs, sense of meaning in life, strength to face difficulties, and understanding life difficulties. These results led us to conclude that the patients surveyed probably use their beliefs to cope with the disease, especially when this belief is more intense and promotes emotional, social and spiritual security, giving meaning to the suffering caused by chronic disease and being a source of hope in the face of changes in health status when the disease becomes active. ${ }^{28}$

Consistent with this idea, Pinto and Ribeiro ${ }^{29}$ report that "Spiritual beliefs are part of a cognitive-active type of framework that enables people to cope with existential threatening crises, encouraging social and emotional support".

The experience of strong intrinsic religiosity correlates with more rapid remission of depression, ${ }^{30}$ an association particularly important when physical function is compromised or is not improving in these patients. Religiosity can be a support in health situations, ${ }^{29}$ and the invocation of beliefs is not only emotionally and spiritually comforting, but also has an influence on health. ${ }^{31}$

However, there are few studies that focus on spirituality in terms of strategies for coping with stress, and there are also few studies that compare how religiosity can help address difficult situations in lives of sick individuals. ${ }^{32}$

The result on Environment domain (Table 4) that showed the lowest score of perceived QOL is consistent with literature, which suggests that human problems can be contextualized by the mismatch between the needs of people and the physical and social environment. ${ }^{9}$ The perception of this dimension is an individual process and depends on the hierarchy of values, but reflects the current conditions of collective life and its impact on the lives of women surveyed.

The results of this investigation show that perception of QOL in adult SLE women with intense disease activity is worse than the QOL of those who have inactive disease, and 
also show that there were statistical significance in Physical, Psychological, and Environment domain $(\mathrm{P}<0.05)$ (Table 6). Similarly, Rinaldi et al. ${ }^{19}$ when examining the QOL of Italian women in a cohort of 126 patients with the disease and 96 healthy controls, found that mental and physical components were reduced only in patients with active disease.

In the study of Benitha and Tikly, ${ }^{33}$ all domains of QOL were significantly worse in the group with SLE and when the disease was active. However, the results of this investigation differ from those of McElhone et al., ${ }^{25}$ which showed worse QOL in patients with SLE, although with no association with disease activity or damage.

An Australian research that established a correlation of QOL with physical, psychological, and spiritual needs; health services; health information; social support; and lifestyle of 363 women revealed many aspects in which Psychological domain and lifestyle were affected, interfering with daily life of people with SLE. The study stresses the importance of understanding these needs and limitations, so that valid strategies for conducting treatments, interventions, and guidelines can be developed. ${ }^{34}$

Patients with active SLE in this research had worse perceived QOL in the Physical domain (Table 6), resulting from the diversity and simultaneity of manifested symptoms, which included swelling, pain, fatigue, skin changes, limited mobility, depression, fever, visual disturbances, alopecia, wounds, arthritis, weight loss or gain, renal and cardiac changes, hypertension, ascites, bleeding gums, oral/vaginal mucosa lesions, and anemia.

Skin changes and photosensitivity cause embarrassment affecting psychosocial level and self-image; and arthralgia ${ }^{35}$ is translated as a limiting factor of functional status in joint involvement. ${ }^{36,37}$

The study undertaken by Thumboo and Strand ${ }^{26}$ showed that SLE patients have lower functional status than the general population and that disease specific manifestations (activity, renal involvement, fibromyalgia) may influence the QOL reported. The authors call attention to skin lesions and alopecia, which worsen QOL in patients with SLE.

Therefore, all that is limiting in any sphere affects behavior, attitudes, and perceptions. For example, the fatigue, which is a common and limiting factor in SLE, and therefore is the subject of several studies, is not always associated with the immune status or inflammation, but with psychosocial factors, anxiety, depression, non-restorative sleep, and muscle and joint pain. ${ }^{38-40}$

The adaptation process to which women are forced during the stages of disease is a major cause of negative emotional changes, such as fear and anxiety. ${ }^{9}$ The most common reactions in the most critical phases of disease are directed to maintain emotional balance, preserving the satisfying self-image, family and social relations, and remove uncertainty about the future.

When the woman becomes ill and lives with a chronic disease, she is faced with limitations, treatment implications, wear, and suffering. ${ }^{17}$ The Psychological domain, when affected (Table 6), shows that the physical, emotional, social, environmental, and spiritual needs are interrelated, requiring interdisciplinary and multidisciplinary care..$^{41}$

In the study by Cruz, ${ }^{42}$ the women with SLE recognized that the disease has a chronic course and stressed the routine difficult of examinations, visits, medication and hospitalization, but described feeling more anxiety at times of further adjustments resulting from the disease and when they became aware of the vulnerability during the active phases of disease. The passive strategies for facing difficult situations, often driven by emotion, are associated with increased psychological distress and, consequently, worst QOL. ${ }^{16}$

Emotional factors, psychological stress, and disease activity itself are marked by unpredictability, ${ }^{35}$ revealing the need for innovative forms of health care, individual or group, in order to alleviate the suffering.

The interventions that address complaints and grievances promptly are quite often unsatisfactory; therefore, interventions that promote changes for a better QOL are needed.

\section{CONCLUSIONS}

The perception of QOL by adult women with SLE evaluated in this study, in all WHOQOL-100 domains, was affected. Better perception of QOL occurred in the Spirituality domain, and worse QOL in the Environment domain. In the perspective of SLE patients with higher education, perception of QOL was better evaluated in Physical, Psychological, Level of Independency, and Environment domains.

The more intense the activity of the disease, the worse the perceived QOL of women with active disease, while women with inactive disease have better QOL perception. The Physical, Psychological, and Environment domains were the most affected in women with active SLE. Physical, Psychological, and Environment domains were the most affected in women with active SLE.

The assessment of QOL based on the individual permits the knowledge of disease and treatment impact in a different but complementary way to the biological, preserving the human character, identifying relevant issues, and enabling interventions to become more effective and comprehensive. 


\section{REFERÊNCIAS}

\section{REFERENCES}

1. Lam GK, Petri M. Assessment of systemic lupus erythematosus. Clin Exp Rheumatol 2005; 23(5):S120-132.

2. Zheng Y, Ye DQ, Pan HF, Li WX, Li LH, Li J et al. Influence of social support on health-related quality of life in patients with systemic lupus erythematosus. Clin Rheumatol 2009; 28(3):265-9.

3. Hahn BH, Karpouzas GA, Tsao BP. Pathogenesis of Systemic Lupus Erythematosus. In: Harrys Júnior ED (ed.). Kelley's Textebook of Rheumatology. 7.ed. Philadelphia, Pensilvania: Elsevier, 2005; p.1174-247.

4. Leong KP, Kong KO, Thong BY, Koh ET, Lian TY, The CL et al. Development and preliminary validation of a systemic erythematosus-specific quality-of-life instrument (SLEQOL). Rheumatology (Oxford) 2005; 44(10):1267-76.

5. Sato EI, Bonfá ED, Costallat LTL, Silva NA, Brenol JCT, Santiago $\mathrm{MB}$ et al. Consenso brasileiro para o tratamento do lúpus eritematoso sistêmico (LES). Rev Bras Reumatol 2002; 42(6):362-70.

6. Ayache DCG, Costa, IP. Alterações da personalidade no lúpus eritematoso sistêmico. Rev Bras Reumatol 2005; 45(5):313-8.

7. Lahita RG. Systemic Lupus Erythematosus. 4. ed. New York: Academic Press; 2004.

8. Minayo MCS, Harz ZMA, Buss PM. Qualidade de vida e saúde: um debate necessário. Ciência Saúde Coletiva 2000; 5(1):7-18.

9. Vinaccia S, Orozco LM. Aspectos psicosociales asociados com la calidad de vida de personas com enfermedades crónicas. Diversitas 2005; 1(2):125-37.

10. Diniz, DP, Schor N. Qualidade de vida. Série guias de medicina ambulatorial e hospitalar-UNIFESP - Escola Paulista de Medicina. Barueri: Manole, 2006.

11. Belasco AGS, Sesso RCC. Qualidade de vida: princípios, focos de estudo e intervenções. In: Diniz DP, Schor N (orgs.). Qualidade de vida. Série guias de medicina ambulatorial e hospitalar - UNIFESP - Escola Paulista de Medicina. Barueri: Manole, 2006; p. 1-10.

12. The Whoqol Group. The World Health Organization quality of life assessment (WHOQOL): position paper from the World Health Organization. Soc Sci Med 1995; 41(10):1403-9.

13. Addington-Hall J, Kalra L. Measuring quality of life: Who should measure quality of life? BMJ 2001; 322:1417-20.

14. Bombardier C, Gladman DD, Urowitz MB, Caron D, Chang CH and the Committee on Prognosis Studies in SLE. Derivation of the SLEDAI. Arthritis and Rheumatism. 1992; 35(6):630-64.

15. Abu-Shakra M, Keren A, Livshitz I, Delbar V, Bolotin A, Sukenik S et al. Sense of coherence and its impact on quality of life of patients with systemic lupus erythematosus. Lupus 2006; 15(1):32-7.

16. Martins CSC. Impacto do suporte social e dos estilos de coping sobre a percepção subjetiva de bem-estar e qualidade de vida em doentes com lúpus. Psicologia.com.pt: o portal dos psicólogos, 2007. Disponível em http://www.psicologia.com.pt/artigos/textos/A0339. pdf. Acessado em: 21 de abril de 2007.

17. Gikovate F. Reflexões sobre o feminino. Entendendo a mulher... além da paciente. São Paulo: Lemos Editorial, 1999.

18. Ward MM, Marx AS, Barry NN. Psychological distress and changes in the activity of systemic lupus erythematosus. Rheumatology 2002; 41(2):184-8.

19. Rinaldi S, Doria A, Salaffi M, Ermani L, Iaccarino A, Ghirardello A et al. Health-related quality of life in Italian patients with systemic lupus erythematosus. I. Relationship between physical and mental dimension and impact of age. Rheumatology 2004; 3(12):1574-9.
20. Khanna S, Pal H, Pandey RM, Handa R. The relationship between disease activity and quality of life in systemic lupus erythematosus. Rheumatology (Oxford) 2004; 43(12):1536-40.

21. Panopalis P, Clarke AE. Quality of life in systemic lupus erythematosus. Clin Dev Immunol 2006; 13(2-4):321-4.

22. Griffiths B, Mosca M, Gordon C. Assessment of patients with systemic lupus erythematosus and the use of lupus disease activity indices. Best Pract Res Clin Rheumatol 2005; 19(5):685-708.

23. Edworthy SM. Clinical manifestation of systemic lupus erythematosus. In: Harris Junior ED (ed.). Kelley`s Textbook of Rheumatology. 7.ed. Philadelphia, Pennsylvania: Elsevier, 2005, p. 1201-47.

24. Archenholtz B, Burckhardt CS, Segesten K. Quality of life of women with systemic lupus erythematosus or rheumatoid arthritis: domains of importance and dissatisfaction. Qual Life Res 1999; 8(5):406- 11.

25. McElhone K, Abbott J, Teh LS. A review of health related quality of life in systemic lupus erythematosus. Lupus 2006; 15(10):633-43.

26. Thumboo J, Strand V. Health-related quality of life in patients with systemic lupus erythematosus: an update. Ann Acad Med Singapore 2007; 36(2):115-22.

27. Huf DD. A face oculta do cuidar: reflexões sobre a assistência espiritual em enfermagem. Rio de Janeiro: Mondrian, 2002, p. 73-108.

28. Fleck MPA, Borges ZN, Bolognesi G, Rocha NS. Desenvolvimento do WHOQOL, módulo espiritualidade, religiosidade e crenças pessoais. Rev Saúde Pública 2003; 37(4):446-55.

29. Pinto C, Ribeiro JLP. Construção de uma escala de avaliação da espiritualidade em contextos de saúde. Arquivos de Medicina 2007; 21(2):47-53.

30. Saad M, Masiero D, Battistella LR. Espiritualidade baseada em evidências. Acta Fisiátrica 2001; 8(3):107-12.

31. Roberto GL. Espiritualidade e saúde. In: Teixeira EFB, Silva JDT, Müller MC (orgs.). Espiritualidade e Qualidade de Vida. Porto Alegre: EDIPUCRS, 2004, p.151-63.

32. Rocha NS, Fleck MPA. Religiosidade, saúde e qualidade de vida: uma revisão da literatura. In: Teixeira EFB, Silva JDT, Müller MC (orgs.). Espiritualidade e Qualidade de Vida. Porto Alegre: EDIPUCRS, 2004, p.165-69.

33. Benitha R, Tikly M. Functional disability and health-related quality of life in South Africans with rheumatoid arthritis and systemic lupus erythematosus. Clin Rheumatol 2007; 26(1):24-9.

34. Moses N, Wiggers J, Nicholas C, Cockburn J. Development and psychometric analysis of the systemic lupus erythematosus needs questionnaire (SLENQ). Qual Life Res 2007; 16(3):461-6.

35. Araújo AD, Traverso-Yépez MA. Expressões e sentidos do lúpus eritematoso sistêmico (LES). Estudos de Psicologia 2007; 12(2):119-27.

36. Santos MJ, Capela S, Figueira R, Nero P, Alves de Matos A, Silva, C et al. Caracterização de uma população portuguesa de doentes com lúpus eritematoso sistêmico. Acta Reum Port 2007; 32(2):153-1.

37. Sato EI, Bonfá ED, Costallat LTL, Silva NA, Breno JCT, Santiago $\mathrm{MB}$ et al. Lúpus eritematoso sistêmico: tratamento do acometimento cutâneo/articular. Rev Bras Reumatol 2004; 44(6):454-7.

38. Omdal R, Waterloo K, Koldingnes W, Husby G, Mellgren SI. Fatigue in patients with systemic lupus erythematosus: the psychosocial aspects. J Rheumatol 2003; 30(2):283-7. 
39. Jump RL, Robinson ME, Armstrong AE, Barnes EV, Kilboum KW, Richards HB. Fatigue in systemic lupus erythematosus: contribuitions of disease activity, pain, depression, and perceived social support. J Rheumatol 2005; 32(9):1699-705.

40. Da Costa D, Dritsa M, Bernatsky S, Pineau C, Ménard HA, Dasgupta $\mathrm{K}$ et al. Dimensions of fatigue in systemic lupus erythematosus: relationship to disease status and behavioral and psychosocial factors. J Rheumatolol 2006; 33(7):1282-8.
41. Hale ED, Treharne GJ, Norton Y, Lyons AC, Douglas KM, Erb N et al. "Concealing the evidence": the importance of appearance concerns for patients with systemic lupus erythematosus. Lupus 2006; 15(8):532-40.

42. Cruz BP. Estrutura do vivido: análise do relato de pacientes com lúpus eritematoso sistêmico [dissertação]. São Paulo: Departamento de Nefrologia, Universidade Federal de São Paulo, São Paulo; 2003. 